GPPS-CH-2020-0079

\title{
EXPERIMENTAL INVESTIGATION OF A TRANSONIC COMPRESSOR WITH VARIABLE STATOR VANES IN TANDEM ARRANGEMENT
}

\author{
Jonas Foret \\ Technical University of Darmstadt \\ Institute of Gas Turbines and \\ Aerospace Propulsion \\ Darmstadt, Germany \\ compressor@glr.tu-darmstadt.de \\ Fabian Klausmann \\ Heinz-Peter Schiffer \\ Technical University of Darmstadt \\ Institute of Gas Turbines and \\ Aerospace Propulsion \\ Darmstadt, Germany
}

\author{
Daniel Franke \\ Technical University of Darmstadt \\ Institute of Gas Turbines and \\ Aerospace Propulsion \\ Darmstadt, Germany
}

\author{
Bernd Becker \\ Hauke Müller \\ Rolls Royce Deutschland Ltd \& Co KG \\ Dahlewitz, Germany
}

\begin{abstract}
This paper investigates the effects of a 1.5-stage transonic axial compressor with a variable tandem stator arrangement. The experiments were carried out at the transonic research compressor rig at Technical University of Darmstadt. The test rig represents a front stage highpressure compressor of jet engines. Using extensive instrumentation, the global performance is analyzed.

A new designed compressor stage has been commissioned, including a BLISK rotor and tandem stator vanes with variable stagger angles. In comparison with a reference stage using a conventional stator design, the new stator design enables a higher aerodynamic stator vane loading. Therefore an optimized stage loading is pursued, leading to an increased work coefficient whilst retaining the operating range of the stage. The experimental study reveals several effects of the optimized compressor stage, considering both, performance and corresponding aerodynamics. The operating range with varying VIGV-VSV schedules differs to the reference case. At nominal tandem stator vane closure, stage pressure rise is increased for the whole operating range. Comparing the stage exit aerodynamics of the tandem and reference stator at design speed, distinct differences appear.

In conclusion, the conducted experimental investigations prove potential capabilities of transonic compressors, enabling optimized stage loading.
\end{abstract}

\section{INTRODUCTION}

The steadily rising air traffic is in conflict with environmental issues. Thus, politically defined goals to reduce emissions, especially carbon dioxide and nitrogen oxides, are becoming increasingly important. To achieve these goals, an enhancement of aero engine's efficiency is essential. As one of its main components, the compressor with its high power consumption strongly contributes to improve thermal efficiency of aero engines. This in turn is obtained by either improving the efficiency or the overall pressure ratio by means of a higher number of compressor stages or increased individual stage loading. For a given overall pressure ratio of a conventional loaded compressor a weight reduction can be realized by reduced blade or vane count, which results in increased blade and vane loading respectively. Therefore an optimized stage loading is a key enabler for modern compressors.

The demand for highly loaded compressor stages leads to a vulnerability to flow separation. One possibility to reach the desired loading is the use of stator vanes in tandem arrangement. Thus, it is possible to enable high aerodynamic loading without flow separation. On the other hand, this allows a higher loading of the corresponding rotor, hence an optimized stage loading.

Compressor vanes in tandem arrangement have been research subject for decades. Ohashi (1959) investigated the relative positioning of tandem vanes to each other experimentally and theoretically. By using a cascade test 
setup, it was possible to examine the respective interference with respect to loss reduction. This was extended by a potential theoretical calculation method. Linnemann (1964) also carried out experimental investigations at an axial compressor with tandem vane rows. By systematically varying the relative tandem vane positioning, an optimum in pressure rise and efficiency was demonstrated. Linnemann showed that tandem vanes are beneficial and only have a slight impact on the stability limit of the stage.

An analytical study of the effects in tandem stators was done by Sanger (1971). His study showed that the objective of loss reduction can be achieved by using tandem vanes. Wu et al. (1985) confirmed these findings experimentally, whereby the arrangement enabling maximum flow turning does not coincide with the arrangement enabling the minimum loss coefficient. This leads to the suggestion of adapting the relative single vane positioning depending on the respective requirements.

The experimental and numerical investigations by Sachmann and Fottner (1983) pointed out that the total pressure loss in tandem cascades differs from each other, if the two vanes are considered together or taken into account separately.

The potential of tandem vanes, reaching a high flow turning while maintaining acceptable losses, was shown by Weber and Steinert (1997) at a transonic cascade.

Sakai et al. (2003) investigated the gap between both tandem vanes as one key feature to control the flow separation mechanisms. Canon and Willinger (2005) confirmed these findings, extended them by the examination of the interaction mechanisms between both vanes and derived an optimized positioning recommendation.

Detailed investigations of tandem airfoils for compressor rotors were performed by McGlumphy (2008), but the basic findings are valid for non-rotating vane rows as well. Beside the already mentioned key aspects, he investigated the sensitivity of the axial overlap and pitchwise displacement of the tandem vanes at design and off-design conditions, performing three-dimensional numerical analysis. His work can be seen as a proof of concept regarding the potential of tandem airfoils used in highly loaded compressors.

The works of Hoeger and Baier (2011) and Müller et al. (2011) presented an aerodynamic design for a high turning compressor tandem cascade and the respective investigations, both numerically and experimentally. The analysis showed a high sensitivity to varying inlet Mach numbers. Hence, design processes should take into account that a beneficial performance of the tandem vanes is strongly depending on their respective operating Mach numbers.

A disadvantage of tandem vanes is revealed by Baumert (2012). The losses of the tandem vane compared to a single vane are only lower at high turning requests. Otherwise the losses of the two vanes in tandem arrangement exceed the losses of the single vane.
Schneider and Kožulović (2013), Hertel et al. (2013), Hertel et al. (2014) and Hertel et al. (2016) carried out numerous investigations of a subsonic compressor tandem cascade, focusing on the flow breakdown mechanisms. They found that tandem vanes can outperform single vanes, but are very sensitive to varying incidence flow angles and Mach number variations. Thus, loss phenomena are hardly predictable, especially in end wall region. Furthermore they showed that the flow of the front blade is clearly influenced by incidence variation, whereas the rear blade is barely influenced.

Experimental investigations at a subsonic axial compressor were performed by Tesch et al. (2014) with respect to the basic flow topology of the tandem stator. They proved a good performance for the tandem stator at varying flow conditions.

Heinrich et al. (2015), Tiedemann et al. (2017), Heinrich et al. (2017) as well as Heinrich and Peitsch (2019) investigated the flow topology of tandem blades at a cascade with respect to secondary flow structures. They showed that the gap flow has a strong influence on the boundary layer of the rear blade, resulting in different corner vortex formation. Hence, passage blockage can be reduced compared to conventional single bladed stators.

The proof of concept of using tandem vanes in a subsonic compressor has been provided by Hopfinger and Gümmer (2019). They showed the capability of withstanding high aerodynamic vane loading while less prone to varying incidence.

As evident by this literature review, a lot of work has been done to derive design proposals for tandem vanes in compressors, analytically and experimentally as well as numerically. Nevertheless, no publications concerning tandem vanes used in rotating high-speed test environments are available.

The objective of this study is the experimental investigation of a transonic compressor stage with high stage loading, using a variable stator vane in tandem arrangement. For a global comparison, a reference stage with conventional stator design is used, as already investigated within previous measurement campaigns, for example Brandstetter et al. (2018) and Jüngst (2019).

\section{EXPERIMENTAL SETUP}

The experimental investigations were carried out at the Transonic Compressor Darmstadt test rig. The test rig as well as the corresponding measurement section is depicted as a sectional view in Figure 1. The test facility is implemented as an open-loop cycle, whereby the air is sucked in from the ambient, led through a settling chamber to the compressor core. Subsequently, the compressed air is discharged to the ambient via an outlet diffuser. The compressor is driven by a direct current motor, providing an electric power of up to $800 \mathrm{~kW}$. With an interposed planetary gearbox rotational speeds of up to $21,000 \mathrm{rpm}$ are achieved. This leads to relative Mach numbers within rotor tip regions of about 1.4, thus enabling transonic conditions. 


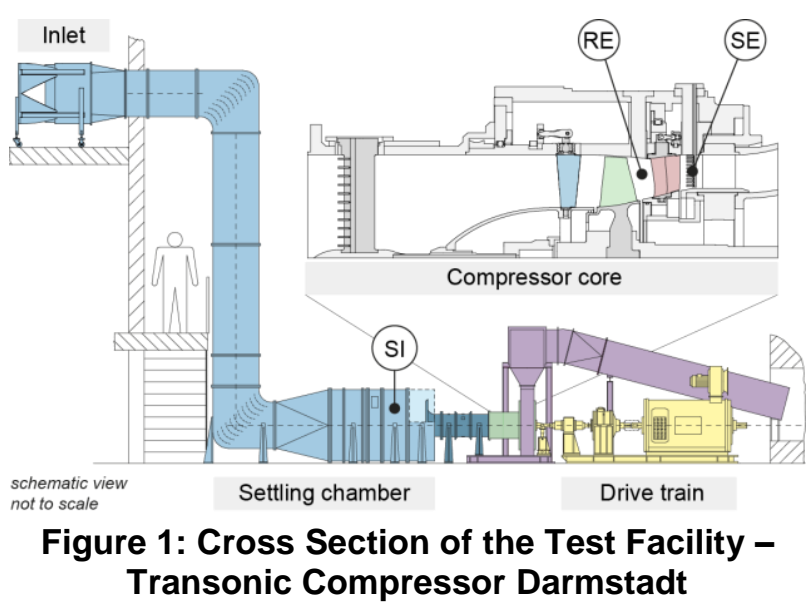

The compressor core has a modular design. Hence, corresponding components like blade and vane rows as well as casing inserts and the instrumentation can be adapted for the respective requirements.

The investigated compressor is set up as a 1.5-stage configuration, consisting of a variable inlet guide vane (VIGV), a BLISK rotor and a variable stator vane (VSV), representing a high pressure compressor front stage of a modern jet engine. The special feature of the VSV is the arrangement as a tandem vane row, which allows a higher stator loading and consequently a higher stage loading in general.

\section{Instrumentation}

To determine the compressor's performance, global operating parameters like pressure and temperature as well as torque have to be measured. The total pressure and total temperature is measured within different axial measurement stations throughout the compressor stage, e.g. stage inlet (SI) or stage exit (SE), as shown in Figure 1, using pitot probes and thermocouples installed in measurement rakes. These rakes are mounted at fixed circumferential positions in the compressor casing, enabling measurements over the radial channel height. To examine the rotor exit (RE) flow field, the VSV leading edges are also instrumented with pitot probes and thermocouples. Additionally static pressure taps are circumferentially distributed in several measurement stations at the hub and casing.

By means of a torque measurement shaft, the rotational speed as well as the torque provided to the compressor is measured.

\section{Test Matrix}

The investigations carried out in the framework of this work comprise a reference stage (REF) and a newly designed stage, the so called optimized loading compressor (OLC), designed by Rolls-Royce Deutschland Ltd \& Co KG. Both configurations are compared with respect to performance data for design speed (DS) and part speed (PS). Afterwards an optimization comprising VIGV and VSV angle variations is performed with the objective of determining the highest possible pressure ratio and efficiency respectively, while maintaining operating range similar to the REF stage.

Table 1 summarizes the measurement content at a glance. As far as possible, the specified color code was maintained throughout the entire work. Sections deviating from this convention are appropriately marked.

Table 1: Summary of Measurement Content

\begin{tabular}{c|c|c|c|c|c}
\hline \multirow{2}{*}{ CONFIG. } & \multirow{2}{*}{ AERO } & \multirow{2}{*}{ VIGV } & \multirow{2}{*}{ VSV } & \multicolumn{2}{|c}{ COLOR CODE } \\
& SPEED & & & $\pi_{\mathrm{t}}$ & $\eta$ \\
\hline \multirow{2}{*}{ REF } & DS & nom & - & $\boldsymbol{\Delta}$ & $\boldsymbol{\Delta}$ \\
& PS & nom & - & $\boldsymbol{\nabla}$ & $\boldsymbol{\nabla}$ \\
\hline \multirow{6}{*}{ OLC } & DS & nom & nom & $\bullet$ & $\circ$ \\
& DS & nom & var & $\bullet$ & \\
& DS & var & nom & $\bullet$ & \\
& PS & nom & nom & $\square$ & $\square$ \\
& PS & nom & var & $\square$ & \\
& PS & var & opt & $\square$ & \\
\hline
\end{tabular}

\section{METHODOLOGY}

In Figure 2, the measurement and analysis procedure for performance determination is shown. As mentioned before, the total pressure and total temperature rakes within the stage exit station are fixed mounted to the casing. To achieve a representative average value for the respective quantities, the non-rotating vane rows, i.e. VIGV and VSV, are simultaneously clocked in circumferential direction, relative to the instrumentation. Thus, a two-dimensional flow field of a stator passage is recorded. By averaging the recorded values in circumferential direction for each particular channel height, radial profiles (1D) are derived. By area averaging the whole two-dimensional flow field, representative mean values are calculated, representing single operating points (OD) in the compressor map.

All data shown within this work are referred to the respective values at the peak efficiency operating point (PE) of the REF configuration at design speed conditions. Otherwise, it is pointed out in the corresponding section.

The shown VIGV and VSV angle variations are normalized, in order to refer the differences to the respective nominal angle at particular speeds to the

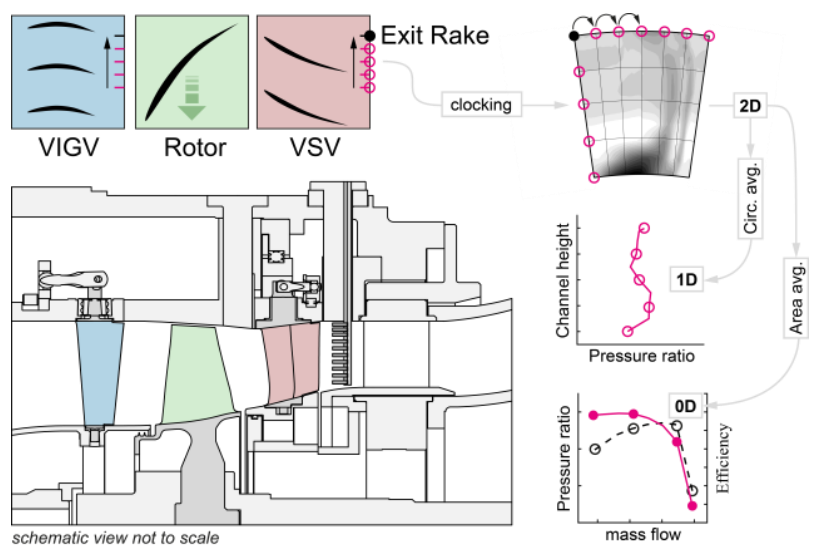

Figure 2: Measurement and Analysis Procedure for Performance Investigations 
adjustment range of the VIGV assembly. The only exception is the VSV variation at part speed. Here the difference to the corresponding optimum is examined.

\section{RESULTS AND DISCUSSION}

In the following, the results are presented and discussed. First, a global comparison between REF and OLC is given for both speed lines, whereby the settings for VIGV and VSV angles are equal (VIGVnom and VSVnom). Afterwards, the influence of VIGV and VSV stagger angle variation on compressor characteristics of the OLC configuration is generally enlighted. Subsequently, distinct differences concerning steady aerodynamics are examined, especially at design speed.

\section{Global Comparison - OLC vs. REF}

Figure 3 shows the compressor characteristics, i.e. pressure rise and efficiency, for OLC and REF at design speed. It is visible that the objective of the OLC configuration, to reach a higher pressure ratio and efficiency is achieved. In particular, the pressure ratio for OLC is higher than for the REF configuration along the whole speed line. Additionally, the efficiency is also increased compared to REF, whereby the reduced mass flows of the peak efficiency operating point (highlighted in Figure 3) matches for both configurations. At peak efficiency of the OLC configuration, the increase in pressure ratio is $8.7 \%$ and the efficiency is increased by $1.1 \%$.

Another remarkable difference between both configurations is visible with respect to stall margin. The stability limit of OLC is already reached at higher reduced mass flows than for REF, given by the last stable operating point, representing steady near stall operating conditions (NS, highlighted in Figure 3). The reason for this effect is not analyzed in the framework of this work, and needs to be investigated in future analysis.

The findings at design speed are also confirmed by the part speed data, shown in Figure 4. Regarding pressure ratio and efficiency, both quantities are increased along the entire part load speed line for the OLC stage compared

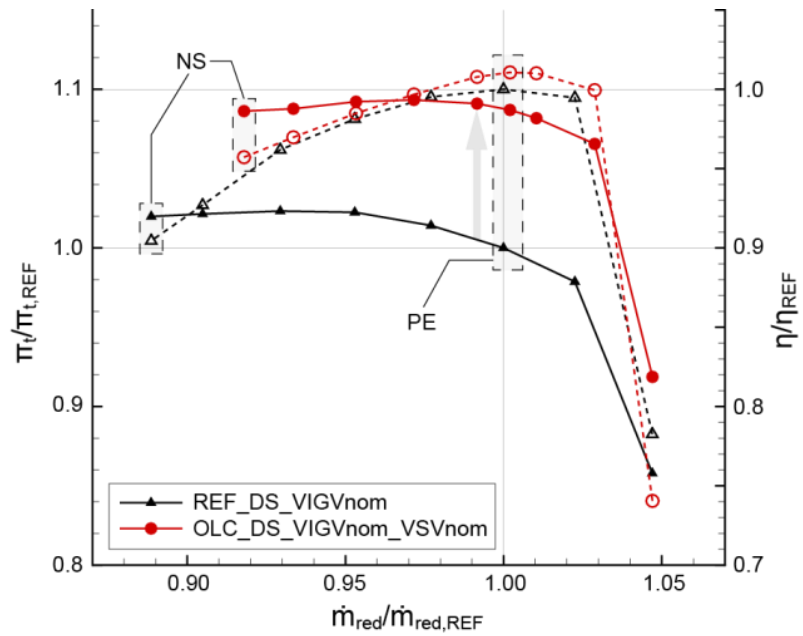

Figure 3: Compressor Map at DS - OLC vs. REF

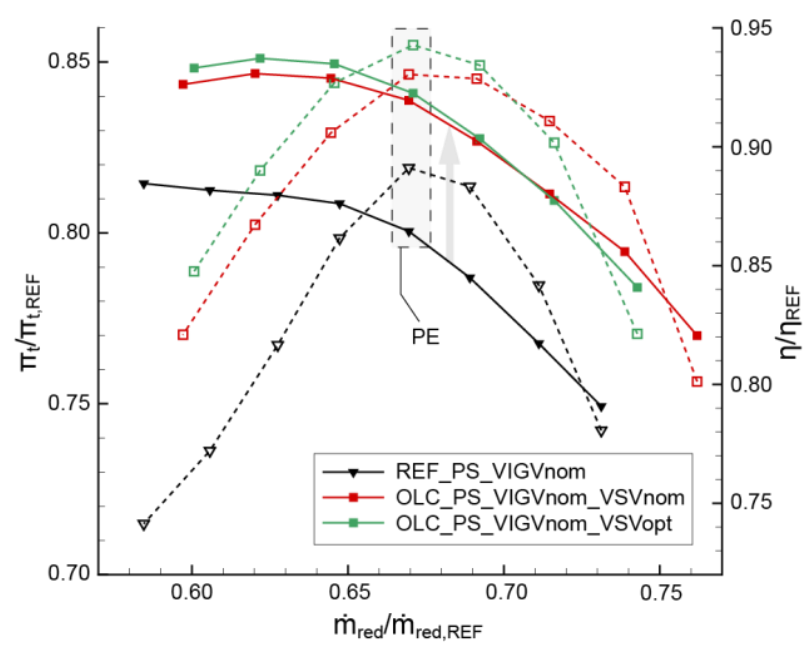

Figure 4: Compressor Map at PS - OLC vs. REF

to the REF configuration. Again, the reduced mass flows at peak efficiency operating conditions agree, whereas the reduced mass flows at the stability limit are higher for OLC than for REF, thus resulting in a smaller stall margin. However, the loss in stall margin is very low. Since the mass flow at near choke operating conditions is also higher for OLC than for REF, a shift in mass flow might be achieved by adjusting the VIGV. Thus, the stage operating range, especially at part speed conditions, can be retained. At peak efficiency, the increase in pressure ratio is $4.9 \%$, in efficiency even $4.4 \%$.

From previous observations it can be concluded that the OLC configuration reaches a higher pressure rise for the whole operating range. Further investigations will aim at both, the contribution of the tandem stator to the higher pressure rise and the loss of stall margin with respect to the REF stage.

\section{Influence of VIGV-VSV Stagger Angle Variation on Performance}

Since the concept of the optimized stage is proved, a variation of VIGV and VSV stagger angle is performed for OLC. At first the nominal VIGV setting of the REF configuration is applied and kept constant while changing the VSV setting. Afterwards, the derived optimum VSV angle is kept constant while adjusting the VIGV stagger angle. In the following section, the influence of these variations on OLC performance is shown for both, design speed and part speed operation.

In Figure 5, the compressor characteristics for different schedules at design speed are depicted. For the sake of clarity, only the respective minimum and maximum VIGV and VSV angle variations of the entire test scope are shown.

As expected, the influence of VSV stagger angle variation is low with respect to pressure rise. There are only slight changes in pressure rise for choked operating conditions (highlight NC in Figure 5). This is attributed to changed throttling conditions, i.e. an increased backpressure due to increasing VSV stagger angle. 


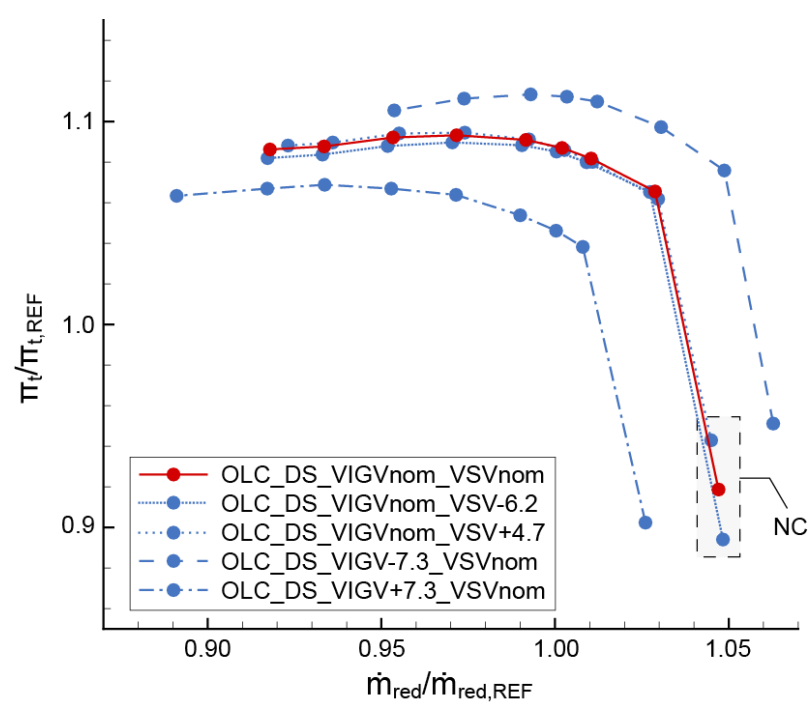

Figure 5: Compressor Map for OLC at DS VIGV-VSV Variation

Concerning efficiency at each peak efficiency operating point, compared in Figure 6, the influence of VSV angle variation is also low, nevertheless visible. There is no symmetry apparent, i.e. a closed VSV has lower influence on efficiency than an opened VSV. From this it can be concluded that the VSV is more vulnerable to positive incidences, caused by opened VSV angles. This matches the findings of Schneider and Kožulović (2013). Their investigations show a lower susceptibility to positive than to negative incidences at subsonic stator inlet Mach numbers. This is attributed to the varying mass flow within the vane gap, i.e. varying momentum of the gap nozzle flow. Here, the maximum loss in efficiency $(-0.4 \%$ referred to OLCnom) is at a VSV closure of $-6.2 \%$. The maximum efficiency is achieved at the VSV setting $+1.1 \%$. Due to the negligible difference with respect to the OLCnom configuration, further investigations in terms of VIGV variation have been carried out with the nominal VSV setting.

Regarding the influence of VIGV stagger angle variation (see Figure 5), the expectations are confirmed. A closed VIGV setting of $+7.3 \%$ leads to lower values in mass flow and pressure ratio, whereas a opened VIGV setting of $-7.3 \%$ leads to a shift in opposite direction. The influence of VIGV variation can be attributed to changing flow angles at the rotor inlet, resulting in different rotor and stage loading as well as different mass flow conditions. With regard to efficiency, the influence of VIGV angle variation is visible in Figure 6. A VIGV closure of $+7.3 \%$ results in an efficiency decrease of $0.1 \%$. A VIGV closure of $-7.3 \%$ results in an efficiency decrease of $0.5 \%$. To find the exact optimum in efficiency, intermediate steps were performed. It is visible that the optimum remains at nominal VIGV closure. Take note that the VIGV closure of $-7.3 \%$ was tested with closed inlet throttle, due to the limited drive train power. Preliminary tests were carried out successfully to exclude

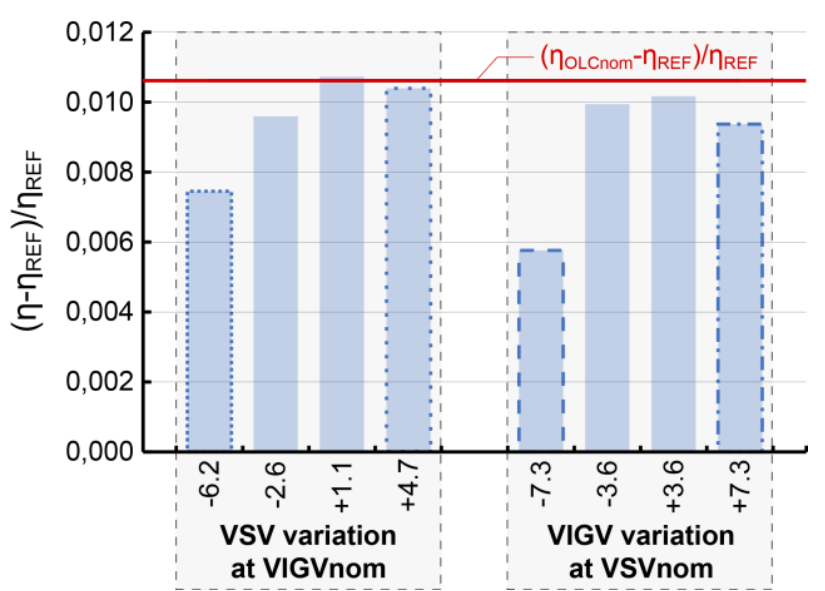

Figure 6: Peak Efficiency Comparison at DS

any influence on reduced parameters. The results of these tests are not shown for brevity.

In contrast to design speed, the VSV stagger angle variation for part speed is not negligible with respect to the compressor characteristics, compare Figure 7.

With increasing VSV angle the characteristic's slope is changing. It seems that there is a pivot point at a normalized mass flow of 0.69 . At near choke conditions this leads to a deceasing pressure ratio with increasing VSV angle considering operating points of equal mass flows (see highlight in Figure 7). At near stall conditions, the opposite trend is visible. There, increasing VSV angles lead to an increased pressure ratio. While the mass flow at the stability limit is barely influenced by the VSV angle, the operating points representing the last points of each characteristic at near choke vary significantly. This is due to the fact that the outlet throttle is already fully opened and the choking point is set by VSV closure conditions. It can be concluded that increased VSV angles lead to increased throttle conditions and therefore to a different pressure ratio at the choking limit.

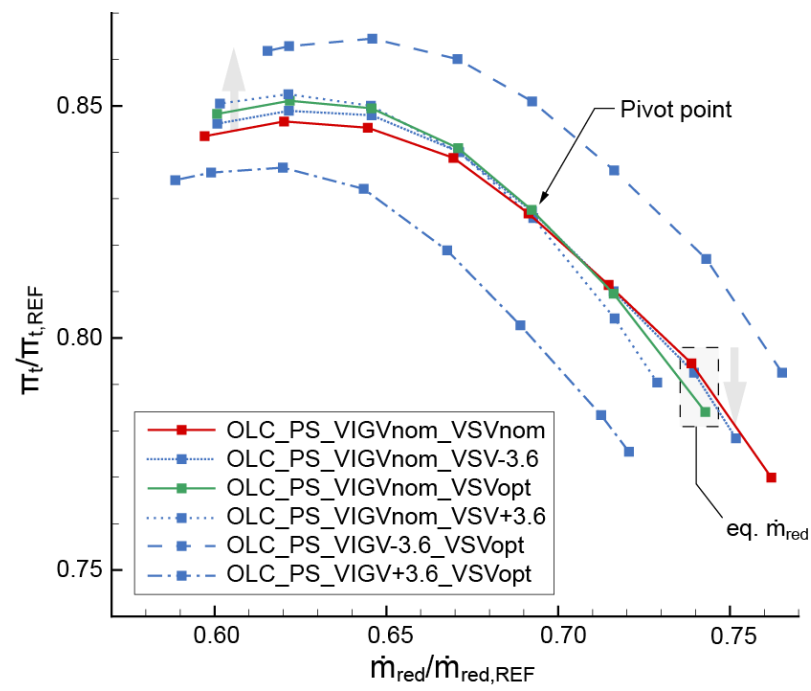

Figure 7: Compressor Map for OLC at PS VIGV-VSV Variation 
Considering the efficiency trends due to varying VSV angles at the respective part speed peak efficiency operating points, one characteristic can be found representing a peak in efficiency, see Figure 8. Compared to the reference VIGV setting, illustrated by the red line, all investigated characteristics with increased VSV closure have an increased peak efficiency. The characteristic with the highest efficiency at its peak efficiency operating point is highlighted as a green bar. This characteristic, also illustrated in the compressor map shown in Figure 4 and Figure 7, is set as the optimized VSV angle setting. Therefore, the following investigations of VIGV angle optimization are carried out with this fixed VSV angle.

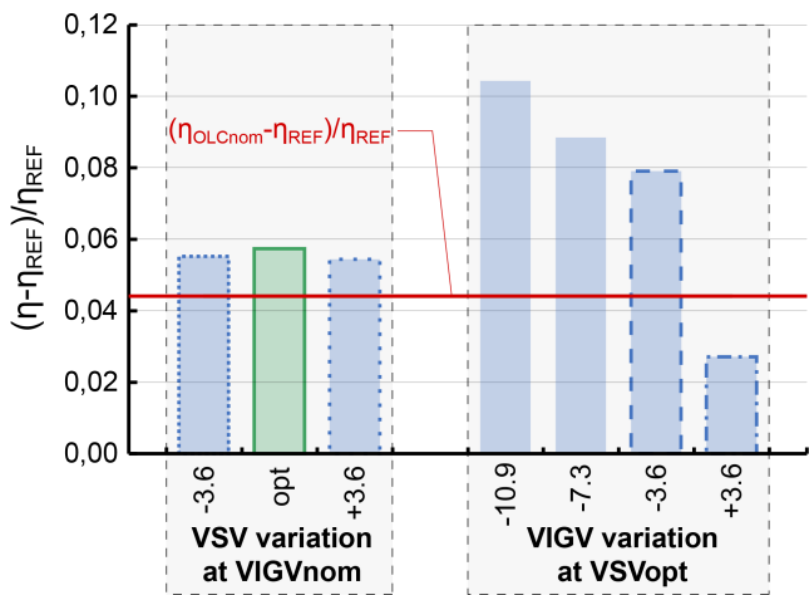

Figure 8: Peak Efficiency Comparison at PS

As expected, the VIGV angle variation at part speed has the same influence on compressor characteristics as seen for design speed (see Figure 7). This means, that the mass flow and the pressure ratio are shifted to lower values with increasing VIGV angles respectively. Again, the influence of VIGV variation can be attributed to changing flow angles at the rotor inlet, resulting in different rotor and stage loading as well as different mass flow conditions. Considering the efficiency change due to varying VIGV angles, it can be seen, that the efficiency is increasing with decreasing VIGV angle, see Figure 8 on the right side. Nevertheless, the nominal VIGV angle, illustrated by the red line, is defined as optimized angle to meet the flow range of the reference stage (compare Figure 4).

\section{Steady Aerodynamics of the OLC Configuration}

Finally, steady aerodynamics, especially at peak efficiency and near stall operating conditions, are investigated in more detail. The examination of radial profiles at rotor and stage exit respectively as well as twodimensional exit flow fields at stage exit should give a deeper insight in the flow phenomena of both, the reference configuration and the optimized loading compressor. For brevity only design speed conditions are provided here.
In Figure 9, the radial pressure distribution for REF and OLC is depicted. Herein the profiles at rotor and stage exit are compared for peak efficiency and near stall. As seen before, it is clearly visible that the OLC configuration reaches a higher pressure ratio for the entire operating range. This applies to both, the rotor and the entire stage. At peak efficiency both configurations show a relatively constant pressure profile at the rotor exit, whereby a slight decrease in the tip gap region can be recognized for OLC (marker A). In order to derive the corresponding aerodynamics of this deficit, further investigations are needed, for example five-hole probe measurements. Regarding the pressure distribution at the stage exit, the expected total pressure loss across the stator is visible, especially in the hub region where a hub flow separation is located (marker B1). This finding is confirmed by the exit flow field which is shown in Figure 12.

At near stall (see Figure 9, right) the aforementioned hub flow separation is more pronounced due to the changed throttling conditions, representing a higher backpressure. It seems that the separation area for OLC is smaller than for REF (markers B2 and B3), which is confirmed by the exit flow field in Figure 12. The radial profile for REF shows a constant pressure distribution in the upper half of the flow channel, whereas a slight increase in the range of 30-40\% channel height can be found for OLC (marker C). This finding is also confirmed by Figure 12. Another conspicuity is visible near the casing end wall (marker D). Both configurations show a distinct pressure peak near the outer annulus at the rotor exit. The stator seems to have larger losses in this area, leading to a pressure profile at stage exit where this pressure peak is smoothed. Again, five-hole probe measurements have to be analyzed to give further insight into these phenomena.

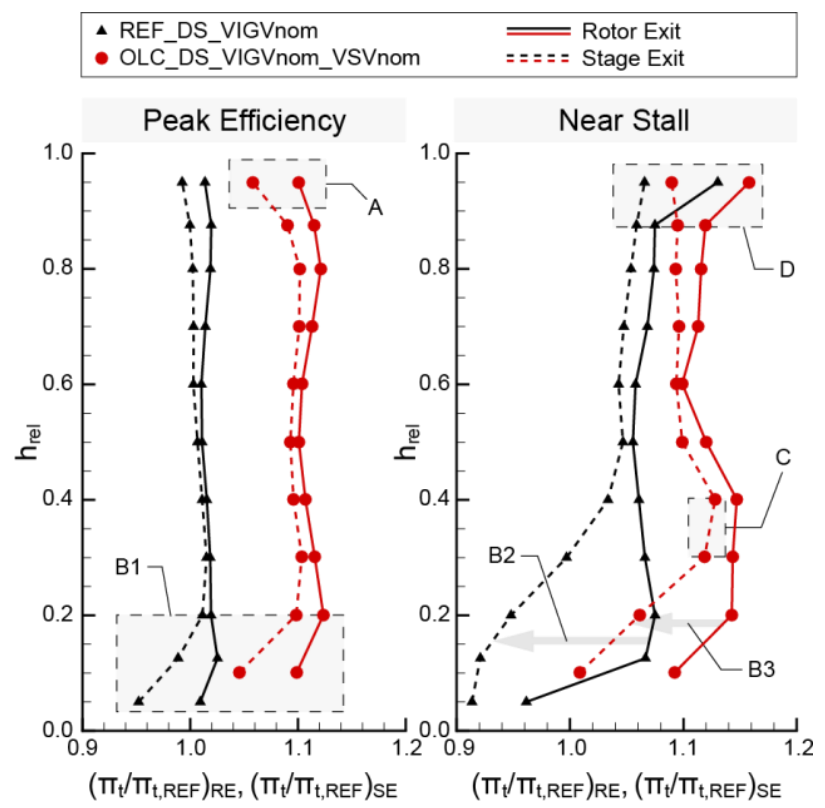

Figure 9: Radial Pressure Distribution at DS OLC vs. REF 
Next, the influence of the VSV variation on pressure rise is investigated, shown in Figure 10. As mentioned before, the VSV variation barely influences the pressure rise of the OLC configuration. Especially at peak efficiency operating conditions, the pressure profiles are almost equal. There are only slight differences visible in the hub region at $20 \%$ channel height (marker E), but solely at the stage exit. The pressure rise provided by the rotor remains unaffected by the VSV variation at design speed. Considering the pressure profiles at near stall, also no changes in the rotor exit section are detectable. In the stage exit, some changes with respect to the nominal OLC configuration are visible. An opened VSV angle of $-6.2 \%$ leads to a slightly decreased pressure rise across the entire channel height. In contrast, at a closed VSV angle of $+4.7 \%$ the upper channel section remains unaffected, whereas an increased pressure rise in the lower $40 \%$ channel height can be seen (marker F). The changes in pressure rise can be attributed to the changed flow angles at the VSV inlet due to the VSV adjustment. Thus, changed incidence conditions causing modified VSV loading and as a result changed total pressure loss behavior.

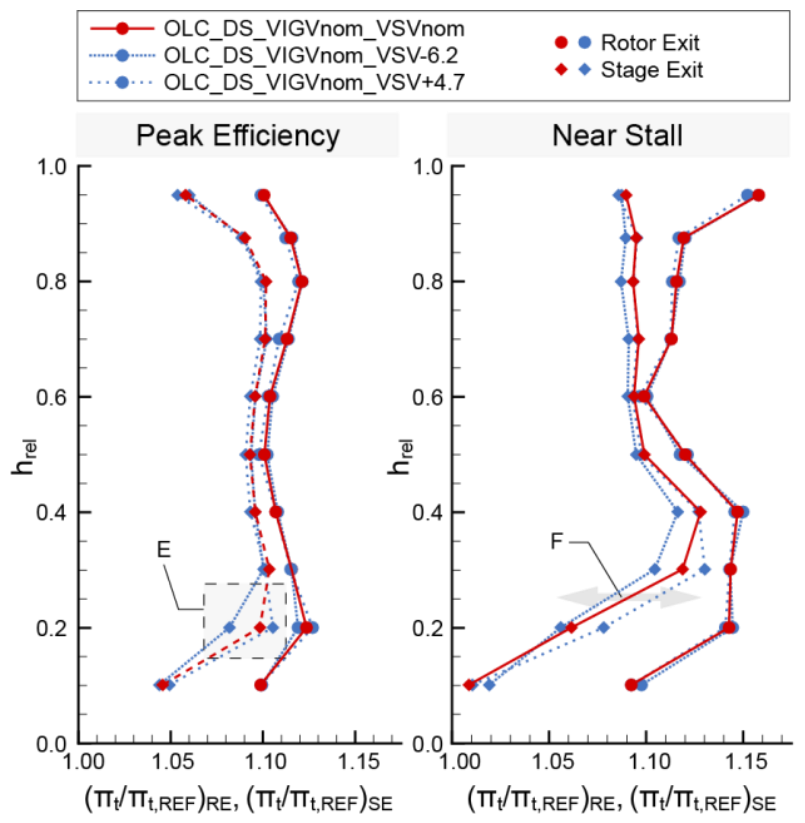

Figure 10: Radial Pressure Distribution at DS VSV Variation

Now, the influence of the VIGV angle variation is examined and shown in Figure 11. For the sake of clarity, only rotor exit profiles are illustrated in this figure, because no influence on stage exit can be detected. As previously seen, the expected shift in pressure rise is confirmed, especially for peak efficiency (marker G). Increasing VIGV angles lead to increased pre-swirl, resulting in a decreased rotor loading. Therefore, the pressure distribution remains nearly the same and is only shifted to lower values. Considering a VIGV closure of $\pm 7.3 \%$ with respect to the nominal schedule (OLCnom), it can be seen that the shift in the respective opposite

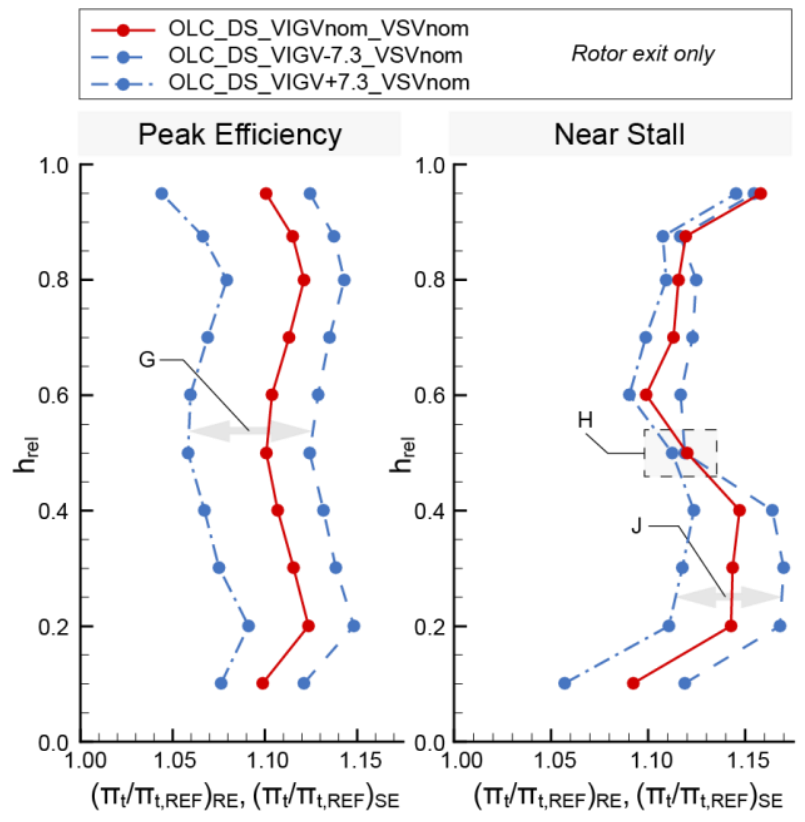

Figure 11: Radial Pressure Distribution at DS VIGV Variation

direction is not symmetrical. As a result, it can be concluded that the investigated rotor might be more sensitive to closed VIGV angles than to opened angles.

Regarding the pressure profiles for near stall, the same trends are visible, but not as uniform as for peak efficiency. In the upper $50 \%$ channel height, changes due to a VIGV angle variation with respect to the nominal VIGV schedule are low with a minimum change at $50 \%$ channel height (marker $\mathrm{H}$ ). In the lower channel section, the influence of VIGV angle variation is more clearly, resulting in variations of more than $2 \%$ (marker $\mathrm{J}$ ).

Some distinct differences considering the twodimensional flow fields at stage exit are elaborated. In Figure 12, the respective pressure fields for OLC and REF are shown at peak efficiency and near stall respectively. The total pressure ratio of the stage is referred to each area averaged mean total pressure value. The scale limits are set to equal values, hence differences between both configurations become visible, taking into account that the OLC configuration achieves a higher total pressure in general.

Regarding the exit flow fields at peak efficiency, the tandem arrangement of the OLC stator is visible by two clearly separated wakes, represented by prominent total pressure loss areas (marker K). For the REF configuration only one wake is visible instead. The aforementioned hub flow separation is also visible for both configurations, but slightly smaller for OLC (marker B1). A possible reason might be the changed pitch of the OLC stator. The tandem vanes allow a reduction of the total stator vane count which leads to a wider flow passage. At near stall, the same findings can be achieved. However, the two wakes of the tandem VSV are not as clearly separated as before. A possible explanation might be the aerodynamically higher loaded vane profiles and boundary layers, which as 


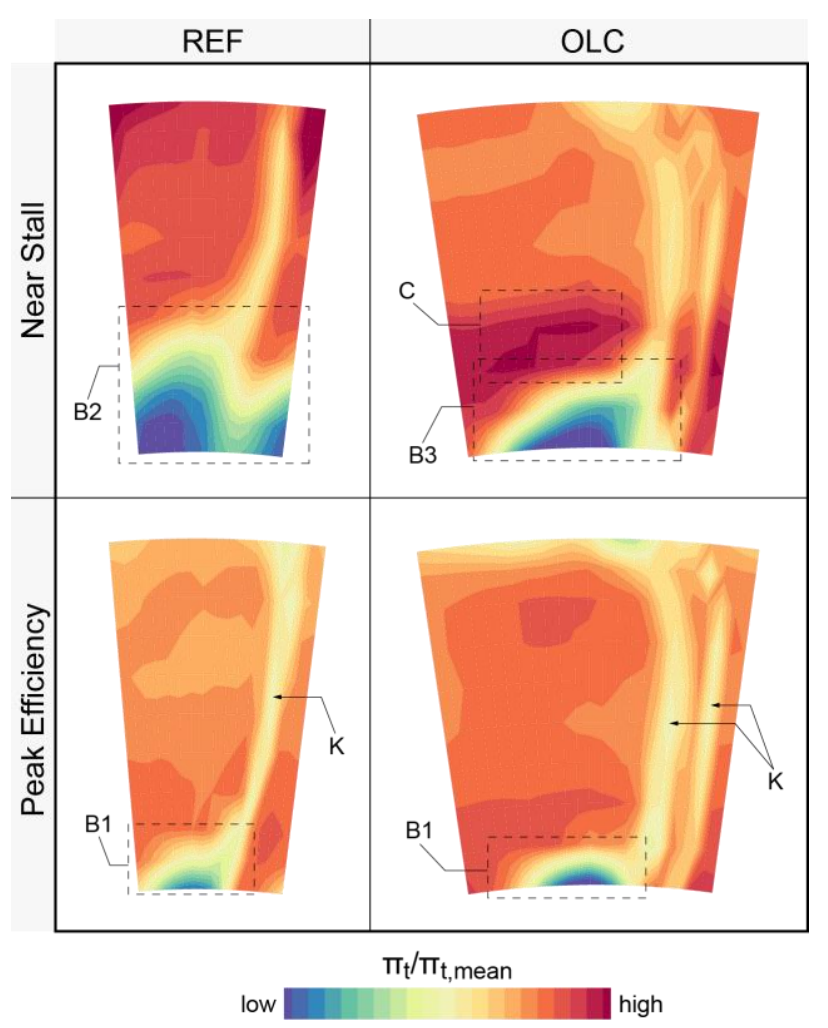

Figure 12: Exit Flow Fields at DS - OLC vs. REF

a consequence leads to more pronounced wakes, thus to a stronger mixing with the second wake. This result matches with the investigations of Tesch et al. (2014), pointing out that pressure loss areas within the stage exit flow field vary in location, size and magnitude. Additionally, the hub flow separation at near stall is more prominent, which is due to the increased back-pressure. Again, the pressure loss area for OLC is less pronounced in circumferential direction considering the pitch (markers B2 and B3).

\section{SUMMARY AND CONCLUSION}

Within this work a 1.5-stage transonic axial compressor with a VSV in tandem arrangement was investigated. Due to the tandem VSV, an optimized loading of the stage (OLC) can be achieved. As reference configuration a transonic compressor stage with a conventional stator design (REF) is used.

The conducted investigation verifies the target of achieving an optimized loading with a stator in tandem arrangement. At design speed peak efficiency, OLC reaches a higher pressure ratio of $8.7 \%$ while the efficiency is also increased by $1.1 \%$ compared to the REF configuration. The optimization process regarding VIGV and VSV stagger angle variation leads to an optimized schedule especially for part speed conditions. Hence, an increase in pressure ratio and efficiency of up to $5.1 \%$ and $5.8 \%$ respectively can be achieved at the peak efficiency operating point for part speed. Additionally, the preservation of the stage operating range, especially at part speed conditions, can be stated.
All in all, the application of tandem stators in transonic axial compressors seems very promising, tackling future challenges in aero engine's compressor designs, enabling high loading. Even though, further investigations have to be carried out to provide deeper insights in the tandem behaviour and its stage interaction. Especially measurements with five-hole probes are recommended, in order to examine the flow field of the tandem stator in more detail. Also, investigations at the stability limit, considering whether the aeroelastic behaviour and stall inception mechanisms of the rotor are influenced by the tandem stator, should follow in future work. Additionally, the loss in stall margin, compared to the REF stage, has to be examined in more detail.

\section{ACKNOWLEDGEMENTS}

This work was funded by Bundesministerium für Wirtschaft und Energie (BMWi) and Rolls-Royce Deutschland Ltd \& Co KG in the framework of the AG-Turbo project COOREFlex-turbo 1.2.6b (FKZ: 03ET7071L and 03ET7070G). The authors gratefully acknowledge the financial support and thank Rolls-Royce Deutschland Ltd \& Co KG for the permission to publish this paper. The technical assistance and helpful discussions with the TU Darmstadt compressor team is very much appreciated. The authors would also like to thank for the continuous support of the compressor aerodynamic group of Rolls-Royce Deutschland.

\section{NOMENCLATURE}

\section{Symbols and Indices}

$\begin{array}{ll}\mathrm{h} & \text { Channel height } \\ \dot{\mathrm{m}} & \text { Mass flow } \\ \eta & \text { Efficiency } \\ \pi & \text { Pressure ratio } \\ \square_{\text {mean }} & \text { Mean value (area averaged) } \\ \square_{\text {red }} & \text { Reduced quantity } \\ \square_{\text {rel }} & \text { Relative quantity } \\ \square_{\mathrm{t}} & \text { Total quantity }\end{array}$

$\begin{array}{ll}\text { Abbreviations } \\ \text { DS } & \text { Design speed } \\ \text { nom } & \text { Nominal configuration } \\ \text { NC } & \text { Near choke } \\ \text { NS } & \text { Near stall } \\ \text { OLC } & \text { Optimized loading compressor } \\ \text { opt } & \text { Optimized configuration } \\ \text { PE } & \text { Peak efficiency } \\ \text { PS } & \text { Part speed } \\ \text { RE } & \text { Rotor exit } \\ \text { REF } & \text { Reference compressor } \\ \text { SE } & \text { Stage exit } \\ \text { SI } & \text { Stage inlet } \\ \text { var } & \text { Variation } \\ \text { VIGV } & \text { Variable inlet guide vane } \\ \text { VSV } & \text { Variable stator vane }\end{array}$




\section{REFERENCES}

Baumert, A. (2012). Abschätzung der Strömungsverluste in VerdichterTandemgittern. Deutscher Luft- und Raumfahrtkongress 2012. Berlin. Document ID: 281512

Brandstetter, C., Jüngst, M., Schiffer, H.-P. (2018). Measurements of radial vortices, spill forward and vortex breakdown in a transonic compressor. ASME Journal of Turbomachinery, 2018, Vol. 140(6): 061004-1. doi: 10.1115/1.4039053.

Canon, G., Willinger, R. (2005). Numerical Investigation of Flow Interference Effects in Tandem Compressor Cascades. $17^{\text {th }}$ International Symposium on Air Breathing Engines 2005. American Institute of Aeronautics and Astronautics. Munich, Germany. September 4-9, 2005. ISABE-2005-1053.

Heinrich, A., Tiedemann, C., Peitsch, D. (2015). Experimental Investigations of Secondary Flow Development Around Tandem Vanes in a 2D Linear Stator Compressor Cascade. $11^{\text {th }}$ European Conference on Turbomachinery Fluid dynamics \& Thermodynamics. Madrid, Spain. March 23-27, 2015. Paper ID: ETC2015-237.

Heinrich, A., Tiedemann, C., Peitsch, D. (2017). Experimental Investigations of the Aerodynamics of Highly Loaded Tandem Vanes in a High-Speed Stator Cascade. Proceedings of the ASME Turbo Expo 2017: Turbomachinery Technical Conference and Exposition. Volume 2A: Turbomachinery. Charlotte, North Carolina, USA. June 26-30, 2017. V02AT39A005. doi: $10.1115 /$ GT2017-63235.

Heinrich, A., Peitsch, D. (2019). Recent Insights into the Flow Topology around Highly Loaded Tandem Vanes. Proceedings of Global Power and Propulsion Society Conference Beijing 2019. Beijing, China. September 16-18, 2019. GPPS-BJ-2019-225.

Hertel, C., Bode, C., Kožulović, D., Schneider, T. (2013). Investigations on Aerodynamic Loading Limits of Subsonic Compressor Tandem Cascades: Midspan Flow. Proceedings of the ASME 2013 International Mechanical Engineering Congress and Exposition. Volume 1: Advances in Aerodynamics. San Diego, California, USA. November 15-21, 2013. V001T01A041. doi: 10.1115/IMECE2013-64488.

Hertel, C., Bode, C., Kožulović, D., Schneider, T. (2014). Investigations on Aerodynamic Loading Limits of Subsonic Compressor Tandem Cascades: End Wall Flow. Proceedings of the ASME Turbo Expo 2014: Turbine Technical Conference and Exposition. Volume 2A: Turbomachinery. Düsseldorf, Germany. June 16-20, 2014. V02AT37A049. doi: 10.1115/GT2014-26978.

Hertel, C., Bode, C., Kožulović, D., Schneider, T. (2016). Particle Image Velocimetry Investigations of a Subsonic Compressor Tandem Cascade. Proceedings of the ASME Turbo Expo 2016: Turbomachinery Technical Conference and Exposition. Volume 2A: Turbomachinery. Seoul, South Korea. June 13-17, 2016. V02AT37A044. doi: 10.1115/GT2016-57726

Hoeger, M., Baier, R.-D. (2011). High Turning Compressor Tandem Cascade for High Subsonic Flows, Part 1: Aerodynamic Design. $47^{\text {th }}$ AIAA/ASME/SAE/ASEE Joint Propulsion Conference \& Exhibit. San Diego, California, USA. July 31 - August 03, 2011. AIAA 2011-5601. doi: 10.2514/6.2011-5601.

Hopfinger, M., Gümmer, V. (2019). Preliminary Design of a ThreeStage Low-Speed Research Compressor Using Tandem Vanes. AIAA Propulsion and Energy 2019 Forum. Indianapolis, Indiana, USA. August 19-22, 2019. AIAA 2019-3909. doi: 10.2514/6.20193909 .

Jüngst, M. (2019). The transonic compressor with non-uniform tip clearance: Effects on aerodynamics and aeroelasticity. $\mathrm{PhD}$ thesis, Technical University of Darmstadt.

Linnemann, H. (1964): Tandemgitter in einem einstufigen Axialgebläse. Partial excerpt from $\mathrm{PhD}$ thesis, TH Braunschweig. Konstruktion 16 (1964), Heft 4, pp. 128-135.
McGlumphy, J., Ng, W.-F., Wellborn, S. R., Kempf, S. (2008). 3D Numerical Investigation of Tandem Airfoils for a Core Compressor Rotor. Proceedings of the ASME Turbo Expo 2008: Power for Land, Sea and Air. Berlin, Germany. June 9-13, 2008. GT2008-50427.

Müller, L., Kožulović, D., Wulff, D., Fischer, S., Stark, U. (2011). High Turning Compressor Tandem Cascade for High Subsonic Flows Part 2: Numerical and Experimental Investigations. $47^{\text {th }}$ AIAA/ASME/SAE/ASEE Joint Propulsion Conference \& Exhibit. San Diego, California, USA. July 31 - August 03, 2011. AIAA 2011-5602. doi: 10.2514/6.2011-5602.

Ohashi, H. (1959). Theoretische und experimentelle Untersuchungen an Tandem-Pumpengittern starker Umlenkung. Ing. arch 27, pp. 201226. doi: $10.1007 / \mathrm{BF} 00538343$

Sachmann, J., Fottner, L. (1993). Highly Loaded Tandem Compressor Cascade With Variable Camber and Stagger. Proceedings of the ASME 1993 International Gas Turbine and Aeroengine Congress and Exposition. Volume 3A: General. Cincinnati, Ohio, USA. May 24-27, 1993. V03AT15A086. doi: 10.1115/93-GT-235.

Sakai, Y., Matsuoka, A., Suga, S., Hashimoto, K. (2003). Design and Test of Transonic Compressor Rotor with Tandem Cascade. Proceedings of the International Gas Turbine Congress 2003 Tokyo. Tokyo, Japan. November 2-7, 2003. IGTC2003Tokyo TS-108.

Sanger, N. L. (1971). Analytical investigation of effects of geometric changes on flow characteristics of tandem bladed compressor stators. NASA Technical Report, NASA-TN-D-6264.

Schneider, T., Kožulović, D. (2013). Flow Characteristics of Axial Compressor Tandem Cascades at Large Off-Design Incidence Angles. Proceedings of the ASME Turbo Expo 2013: Turbine Technical Conference and Exposition. Volume 6A: Turbomachinery. San Antonio, Texas, USA. June 3-7, 2013. V06AT35A011. doi: 10.1115/GT2013-94708.

Tesch, A., Lange, M., Vogeler, K., Ortmanns, J., Johann, E., Gümmer, V. (2014). An Experimental Investigation of a Tandem Stator Flow Characteristic in a Low Speed Axial Research Compressor. Proceedings of the ASME Turbo Expo 2014: Turbine Technical Conference and Exposition. Volume 2A: Turbomachinery. Düsseldorf, Germany. June 16-20, 2014. V02AT37A029. doi: 10.1115/GT2014-26104.

Tiedemann, C., Heinrich, A., Peitsch, D. (2017). Increasing Blade Turning by Active Flow Control and Tandem Configurations: A Comparison. $23^{\text {rd }}$ ISABE Conference, International Symposium on Air Breathing Engines. Manchester, UK. September 3-8, 2017. ISABE-2017-22575.

Weber, A., Steinert, W. (1997).Design, Optimization, and Analysis of a High-Turning Transonic Tandem Compressor Cascade. Proceedings of the ASME 1997 International Gas Turbine and Aeroengine Congress and Exhibition. Volume 1: Aircraft Engine; Marine; Turbomachinery; Microturbines and Small Turbomachinery. Orlando, Florida, USA. June 2-5, 1997. V001T03A067. doi: 10.1115/97-GT-412.

Wu, G., Zhuang, B., Guo, B. (1985). Experimental Investigation of Tandem Blade Cascades With Double-Circular ARC Profiles. Proceeding of the ASME 1985 Beijing International Gas Turbine Symposium and Exposition. Volume 1: Aircraft Engine; Turbomachinery. Beijing, People's Republic of China. September 1-7, 1985. V001T02A036. doi: 10.1115/85-IGT-94 